\title{
Patterns of intracellular cytokines in CD4 and CD8 T cells from patients with mycobacterial infections
}

P.R.Z. Antas ${ }^{1}$, J.S. Sales ${ }^{1}$, K.C. Pereira ${ }^{1}$, E.B. Oliveira ${ }^{1}$, K.S. Cunha' ${ }^{2}$, E.N. Sarno ${ }^{1}$ and E.P. Sampaio ${ }^{1}$

\author{
'Laboratório de Hanseníase, Departamento de Medicina Tropical, \\ Instituto Oswaldo Cruz, FIOCRUZ, Rio de Janeiro, RJ, Brasil \\ ${ }^{2}$ Hospital Municipal Raphael de Paula e Souza, Rio de Janeiro, RJ, Brasil
}

Correspondence

P.R.Z. Antas

Laboratório de Hanseníase

Instituto Oswaldo Cruz, FIOCRUZ

Av. Brasil, 4365

21045-900 Rio de Janeiro, RJ

Brasil

Fax: +55-21-2270-9997

E-mail: pzuquim@ioc.fiocruz.br

Research supported by CNPq and FIOCRUZ.

Received August 13, 2003

Accepted May 3, 2004

...........................

\begin{abstract}
Using a short-term bulk culture protocol designed for an intracellularstaining method based on a flow cytometry approach to the frequencies of cytokine-producing cells from tuberculosis and leprosy patients, we found distinct patterns of $\mathrm{T}$ cell subset expression. The method also reveals the profile of peak cytokine production and can provide simultaneous information about the phenotype of cytokineproducing cells, providing a reliable assay for monitoring the immunity of these patients. The immune response of Mycobacterium leprae and purified protein derivative (PPD) in vitro to a panel of mycobacteria-infected patients from an endemic area was assessed in primary mononuclear cell cultures. The kinetics and source of the cytokine pattern were measured at the single-cell level. IFN- $\gamma-$, TNF- $\alpha-$, IL-4and IL-10-secreting $\mathrm{T}$ cells were intracytoplasmic evaluated in an attempt to identify M. leprae- and PPD-specific cells directly from the peripheral blood. The analysis by this approach indicated that TNF- $\alpha$ was the first $(8 \mathrm{~h})$ to be produced, followed by IFN- $\gamma(16 \mathrm{~h})$, IL-10 (20 h) and IL-4 (24 h), and double-staining experiments confirmed that CD4+ were a greater source of TNF- $\alpha$ than of CD $8+\mathrm{T}$ cells $(\mathrm{P}<0.05)$. Both $\mathrm{T}$ cell subsets secreted similar amounts of IFN- $\gamma$. We conclude that the protocol permits rapid evaluation of cytokine production by different $\mathrm{T}$ cell populations. The method can also be used to define immune status in non-infected and contact individuals.
\end{abstract}

\section{Introduction}

Cytokines are important mediators that play a significant role in the immunoregulation of leukocyte responses (for a review, see Kroemer et al., Ref. 1). Several strategies for studying cytokine production have been proposed (for a review, see Carter and Swain, Ref. 2). Some of the techniques currently employed may interfere with the detection of
Key words

- Tuberculosis

- Leprosy

- IFN- $\gamma$

- TNF- $\alpha$

- Anti-hCD28 mAb ................... cytokine production and secretion. Among them are ELISA and ELISPOT, which are highly specific but only detect secreted cytokines. They reflect the net outcome of production, absorption and degradation of cytokines. Therefore, they are not measuring only the production of cytokines at the single-cell level.

Recently, powerful immunological methods for the assessment of cytokine-produc- 
ing $\mathrm{T}$ cells have also been described for human samples. Intracellular staining for cytokines is a relatively novel method that allows simultaneous staining of several cytokines and surface markers on cells, thus permitting the identification of subpopulations and their cytokine production. A number of these methodologies are based on the count of cytokine-producing cells by flow cytometry (3-5). Sander et al. (6) first demonstrated the detection of intracellular cytokines by fixation (paraformaldehyde), permeabilization (saponin) and immunofluorescent staining using cytokine-specific monoclonal antibodies. Later, a modified method developed in order to improve specific intracellular staining permitted the detection of cytokine-producing cells by singlelaser flow cytometry (3). This methodology is currently being used to study the possible role of specific cytokines in several human diseases (7-9), with a reduction of the time needed for analysis and an improved precision in the detection of cytokines, mainly those produced by CD4+ and CD8+ T cells. However, none of the cited reports has described the kinetics of fast production of major $\mathrm{T}$ cell cytokines using mycobacterial antigens. Only Kemp et al. (10) described a method for long-term purified protein derivative (PPD)-stimulated cultures, since no second signal to trigger the cytokine production had been used.

Cell-mediated immunity plays a major role in limiting the spread of tuberculosis and leprosy in immunocompetent hosts, and many pathological features are the result of cellular immune responses to the presence of Mycobacterium tuberculosis and M. leprae, respectively (11). Recent studies on immunity to mycobacteria have reported that some $\mathrm{T}$ cell functions may play an important role in controlling the infection (12). IFN- $\gamma$ and TNF- $\alpha$ are believed to be essential for the activation of macrophages and for the control of the mycobacterial replication and granuloma formation, respectively, in hu- mans (for a review, see Stenger and Modlin, Ref. 13). On the other hand, IL-4 and IL-10 are believed to increase the bacterial load (12).

Several methods for assessing cytokine expression and production at the single-cell level have been revisited (14); however, only a few laboratories have studied this characterization in depth and, to our knowledge, the present paper is the first to describe a standardized procedure using short-term bulk cultures plus the addition of anti-CD28 $\mathrm{mAb}$ for the detection of specific $\mathrm{T}$ cell subsets producing cytokines in leprosy and tuberculosis patients who are M. leprae and PPD responders.

This protocol for intracytoplasmic staining was first validated to examine the frequencies of cytokine-producing cells from Brazilian tuberculosis patients (15, and Antas P, Cardoso F, Pereira K, Oliveira E, Sarno E, Franken K, Milagres A, Klatser P, Ottenhoff $\mathrm{T}$ and Sampaio E, unpublished data). The method provides the profile of in vitro production of various cytokines by a population of peripheral blood mononuclear cells (PBMC). Also, intracellular staining can provide information similar to that obtained by ELISA and can be used to determine the frequency and immunophenotyping of cytokine-producing cells, representing a reliable assay for the definition of the immune status of these patients.

In the present study, the M. leprae and PPD in vitro immune responses were assessed in 32 leprosy and tuberculosis patients from an endemic area in Brazil. The kinetics and source of cytokines were estimated at the single-cell level in primary PBMC cultures. IFN- $\gamma$-, TNF$\alpha$-, IL-4- and IL-10-secreting $\mathrm{T}$ cells were determined in short-term bulk cultures in an attempt to identify Mycobacterium-specific cells present in peripheral blood. The analysis of cytokine production by intracellular flow cytometry allows rapid identification of functional subsets within heterogeneous $\mathrm{T}$ cell populations. 


\section{Material and Methods}

\section{Study population}

A total of 15 pulmonary tuberculosis and 17 leprosy patients were recruited from the outpatient unit of the District hospital Raphael de Paula e Souza, and Souza Araújo Outpatient Clinic, FIOCRUZ, Rio de Janeiro, RJ, Brazil, respectively. Pulmonary tuberculosis and leprosy were diagnosed according to the criteria established by the World Health Organization (WHO) and the Brazilian Ministry of Health. The detailed methodology for the screening and diagnosis of the tuberculosis and leprosy patients has been described elsewhere $(15,16)$. The patients were treated according to the recommendations of the Ministry of Health. All patients included were HIV negative when tested by two specific ELISA procedures. Patients with clinical conditions such as pregnancy, cancer, diabetes, AIDS, liver or kidney disease, and treatment failure were excluded. All patients provided informed written consent for blood collection and the study was approved by the Ethics Committee of the Institution, and according to resolution 196/96 of the National Health Council of the Ministry of Health.

\section{Antigens}

PPD (RT-46) was purchased from the Statens Serum Institute (Copenhagen, Denmark), and killed M. leprae was purchased from the WHO (Geneva, Switzerland). The antigen concentrations used for PBMC stimulation were $10 \mu \mathrm{g} / \mathrm{ml}$, according to previous titration. The mitogen phytohemagglutinin (PHA, Gibco-BRL, Gaithersburg, MD, USA) was used as a positive control in most of the experiments. The endotoxic potencies (lipopolysaccharide content) in the antigenic preparations were checked using a chromogenic Limulus amebocyte lysate assay kit (Biowhittaker, East Rutherford, NJ, USA), and the final concentrations were found to have no influence on cellular activity.

\section{Short-term cultures and stimulation}

Heparinized venous blood was obtained and PBMC were isolated by Ficoll-Hypaque (Pharmacia Fine Chemicals, Piscataway, NJ, USA) density gradient centrifugation. A total of $1.0 \times 10^{6}$ cells/well were cultivated in 24-well flat-bottom plates (Costar Corp., Cambridge, MA, USA) in $1 \mathrm{ml}$ complete RPMI 1640 (medium supplemented with $20 \%$ autologous plasma, antibiotics and Lglutamine) and incubated at $37^{\circ} \mathrm{C}$ in a humidified $5 \% \mathrm{CO}_{2}$ incubator. $M$. leprae or PPD antigen was added to the wells after 4, $8,10,12,16,20,22,24$, and $48 \mathrm{~h}$. Four hours before the end of the cultures, either $50 \mathrm{ng} /$ $\mathrm{ml}$ PMA plus $1 \mu \mathrm{g} / \mathrm{ml}$ ionomycin (Sigma Immunochemicals, St. Louis, MO, USA) for single staining experiments, or $3 \mu \mathrm{g} / \mathrm{ml}$ purified anti-human CD28 antibody (Pharmingen Inc., San Diego, CA, USA) for double staining experiments were added to the cultures. The inclusion of a protein transport inhibitor during the in vitro stimulation has been reported to enhance the levels of cytokines detected (3). Thus, $4 \mathrm{~h}$ before the end of incubation, $10 \mu \mathrm{g} / \mathrm{ml}$ of brefeldin A (Sigma) was added to the cultures. The cells and supernatants were then recovered separately. The supernatants were kept at $-20^{\circ} \mathrm{C}$ for further assays, and the cells were harvested by washing the wells with $1 \mathrm{ml}$ of cold PBS.

\section{Intracellular cytokine measurements by flow cytometry}

Cells were prepared for intracytoplasmic cytokine analysis according to the Pharmingen Inc. protocol, with modifications (15). After a first PBS washing, the resulting cells were resuspended in cold PBS-FACS (PBS: $0.1 \%$ BSA plus $0.01 \%$ sodium azide). After the determination of cellularity, the amount of cells was adjusted to $0.5 \times 10^{6}$ cells $/ \mathrm{ml}$. 
For cultures stimulated with anti-CD28, the experiments were performed with double staining: a) for cytokines and CD4+, incubated after previous titration with FITC-labeled mouse anti-human CD4 (Becton and Dickinson, San Diego, CA, USA), and b) for cytokines and CD8+ cells, incubated with FITC-labeled mouse anti-human CD8, both in PBS-FACS for $30 \mathrm{~min}$ at $4^{\circ} \mathrm{C}$ in the dark. After two PBS-FACS washings at $4^{\circ} \mathrm{C}$, the cells were fixed in $4 \%$ paraformaldehyde (PFA) by vortexing at room temperature and the same procedure was followed for other staining. After $10 \mathrm{~min}$, the cells were washed twice with PBS-FACS, and washed once with HBSS plus a $0.3 \%$ saponin solution. A total of $100 \mu 1$ of saponin solution was used and cells were incubated for $30 \mathrm{~min}$ at room temperature with the respective PE-labeled antibodies to each cytokine: IFN- $\gamma$, TNF- $\alpha$, IL-4 and IL-10 (Pharmingen). After two saponin solution washings and a subsequent PBS washing, the cells were resuspended with $1 \%$ PFA and the labeled cells were immediately analyzed by flow cytometry in a FACScalibur ${ }^{\circledR}$ instrument (Becton and Dickinson) equipped with the CellQuest ${ }^{\circledR}$ software. Cell gate regions were drawn around viable cells based on their forward scatter (FSC) versus side scatter (SSC) properties in order to exclude cell debris (inset in Figure 3A). In double-staining experiments, an extra-independent circular cell gate region was also drawn around viable blast cells. In addition to detecting the light scattered from the cells, FL-1 (FITC) and FL-2 (PE) signals were set up. A total of 50,000 events in small lymphocyte regions per sample were collected in a dot plot displaying the FSC and SSC properties of the cell. The relative fluorescence intensity of the cells was analyzed in a dot plot using a logarithmic scale for FL. Cell permeabilization may result in higher levels of non-specific staining (5). Thus, it is important to include controls for non-specific binding, and positive (PHA) and negative controls for cytokine production. We set thresholds and statistical markers for positivity using irrelevant isotype FITC- and PE-mouse IgG1 as match control. Data are reported as the percentage of single- or double-stained positive bright cells.

\section{IFN- $\gamma$ production}

IFN- $\gamma$ concentration in cell-free culture supernatant was determined with a commercial ELISA using specific pairs of monoclonal antibodies processed according to manufacturer specifications (Pharmingen). The detection limit of the assay was $8 \mathrm{pg} / \mathrm{ml}$, and cytokine levels in control cultures were usually undetectable.

\section{Statistical analysis}

Results are reported as mean \pm SEM and data were analyzed statistically by the Student $t$-test (GraphPad InStat V. 2.04), with the level of significance set at $\mathrm{P}<0.05$.

\section{Results}

\section{Kinetics of IFN- $\boldsymbol{\gamma}$ and TNF- $\alpha$ production in response to Mycobacterium leprae or purified protein derivative}

To our knowledge, this is the first study describing the kinetics of cytokine production in short-term bulk PBMC cultures using PPD as antigen for tuberculosis patients, and both PPD and M. leprae antigens for leprosy patients. Intracellular cytokine production by human lymphocytes was assessed by FACS involving staining by the permeabilization procedure. It is important to examine the kinetics of cytokine production following antigenic stimulation, since each individual cytokine may have different kinetics during expression (6). The kinetics of IFN- $\gamma$ and TNF- $\alpha$ production by lymphocytes was determined after in vitro stimulation with PHA (data not shown), and PPD or M. leprae in 3 tuberculosis and 4 
leprosy patients, respectively. The immune response to PPD and M. leprae, as assessed by specific ELISA, was positive (IFN- $\gamma>100 \mathrm{pg} /$ $\mathrm{ml}$, and TNF- $\alpha$ above baseline levels) in all tuberculosis and leprosy patients (Figure 1A and data not shown).

Since non-stimulated $\mathrm{T}$ cells usually do not produce measurable amounts of cytokines, in vitro stimulation is required (17). PMA + ionomycin under the influence of brefeldin A was used to artificially stimulate production and stock of cytokines, respectively. The kinetic pattern of IFN- $\gamma$ and TNF$\alpha$ production by lymphocyte populations in vitro assessed by intracellular staining is shown in Figure 1A and 1B, respectively. The kinetics of the response to IFN- $\gamma$ was monitored at 8, 12, 20, and $24 \mathrm{~h}$. The peak of IFN- $\gamma$ levels from one tuberculosis patient in response to PPD occurred at about $16 \mathrm{~h}$. To obtain more precise data, we repeated the experiment using shorter intervals between time points at 12, 16 and $20 \mathrm{~h}$. Sixteen hours was the optimum time to detect IFN- $\gamma$ in this system (Figure 1A). Also, the in vitro kinetics of IFN- $\gamma$ levels was determined in the same supernatants by ELISA, comparing the efficiency of brefeldin $\mathrm{A}$ in retaining the intracellular cytokine (Figure 1A). As expected, cytokine synthesis did not match the cytokine concentration in the supernatants since the peak of IFN- $\gamma$ detected by FACS was observed sooner after stimulation, but the peak in the supernatant seemed to occur after $24 \mathrm{~h}$.

To detect TNF- $\alpha$ production, we followed the same procedure as above, but at earlier times, since the production of this cytokine has been reported to precede IFN- $\gamma(18)$. We monitored TNF- $\alpha$ at $4,8,10,12,16,20,22$, 24 , and $72 \mathrm{~h}$, and the kinetics is shown in Figure 1B. Here, TNF- $\alpha$ was the first cytokine produced by lymphocytes in all leprosy patients. The highest TNF- $\alpha$ production occurred between 4 (despite high background levels) and $12 \mathrm{~h}$, corroborating earlier reports (16). Therefore, the optimum response was at $8 \mathrm{~h}$ as the point of highest TNF- $\alpha$ production. At this time, the cells showed a high percentage of short-term cytokine production, as further confirmed by doublestaining experiments. A positive immune response was detected in the leprosy patients tested with PHA (Table 1).

\section{Kinetics of IL-4 and IL-10 production in response to Mycobacterium leprae or purified protein derivative}

It has been reported that primary stimulation is required for IL-4 and IL-10 produc-
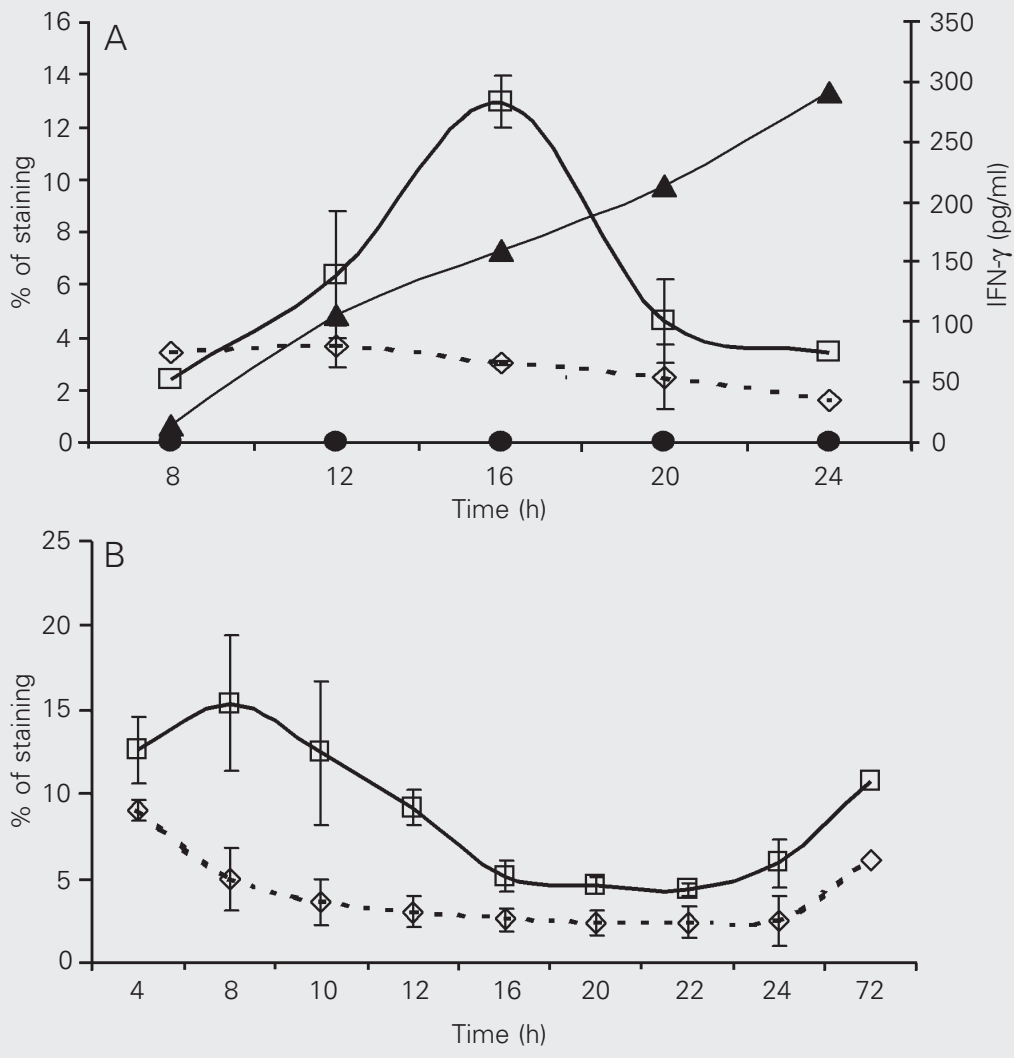

Figure 1. Kinetics of IFN- $\gamma$ (A) and TNF- $\alpha$ (B) production by total lymphocytes from purified protein derivative- or Mycobacterium leprae-stimulated (squares) peripheral blood mononuclear cells of tuberculosis or leprosy patients, respectively. In A, a second axis on the right side of the figure denotes IFN- $\gamma$ levels $(\mathrm{pg} / \mathrm{ml})$ from one representative tuberculosis patient culture supernatant comparing the same previous stimuli (circles) and where brefeldin A was suppressed (triangles). The dashed lines and diamonds indicate the nonstimulated cultures (medium). Data are reported as means \pm SEM $(N=7)$ obtained from medium or Mycobacterium-antigens (at $10 \mu \mathrm{g} / \mathrm{ml}$ ) plus cells additionally stimulated with PMA, ionomycin and brefeldin A. 
Table 1. Percentages of IFN- $\gamma(16 \mathrm{~h})$ and TNF- $\alpha(8 \mathrm{~h})$ staining in CD4+ and CD8+ T cells following in vitro antigen stimulation of peripheral blood mononuclear cells from tuberculosis and leprosy patients.

\begin{tabular}{|c|c|c|c|c|c|c|c|c|}
\hline & \multicolumn{8}{|c|}{ Stimulus } \\
\hline & \multicolumn{4}{|c|}{ Small Iymphocytes } & \multicolumn{4}{|c|}{ Blast lymphocytes } \\
\hline & Medium & PPD & M. leprae & PHA & Medium & PPD & M. leprae & PHA \\
\hline \multicolumn{9}{|l|}{ Tuberculosis patients } \\
\hline $\mathrm{CD} 4+/ \mathrm{IFN}-\gamma(10)$ & $0.46 \pm 0.07$ & $1.67 \pm 0.45^{*}$ & ND & ND & $2.04 \pm 0.3(8)$ & $8.73 \pm 2.2^{*}$ & ND & ND \\
\hline $\mathrm{CD} 8+/ \mathrm{IFN}-\gamma(10)$ & $0.44 \pm 0.08$ & $1.50 \pm 0.38^{*}$ & ND & ND & $1.77 \pm 0.2(8)$ & $7.27 \pm 1.8^{*}$ & ND & ND \\
\hline $\mathrm{CD} 4+/ \mathrm{TNF}-\alpha(5)$ & $0.78 \pm 0.04$ & $2.05 \pm 0.63^{*}$ & ND & ND & $3.11 \pm 0.3(5)$ & $9.87 \pm 2.1^{*}$ & ND & ND \\
\hline CD8+/TNF- $\alpha$ & $0.49 \pm 0.14$ & $1.01 \pm 0.24$ & ND & ND & $2.14 \pm 0.4(5)$ & $7.87 \pm 1.2^{*}$ & ND & ND \\
\hline \multicolumn{9}{|l|}{ Leprosy patients } \\
\hline CD4+/TNF- $\alpha$ (13) & $1.88 \pm 0.48$ & $3.72 \pm 1.24$ & $4.39 \pm 1.24$ & $14.6 \pm 4.73^{*}$ & $8.16 \pm 2.5(9)$ & $11.45 \pm 3.2$ & $18.62 \pm 9.0$ & $36.47 \pm 10.9 *$ \\
\hline CD8+/TNF- $\alpha$ (13) & $0.70 \pm 0.12$ & $1.45 \pm 0.33^{*}$ & $1.79 \pm 0.38^{*}$ & $4.77 \pm 0.75^{*}$ & $4.68 \pm 1.3(9)$ & $11.91 \pm 4.9$ & $6.72 \pm 1.5$ & $14.45 \pm 1.3^{*}$ \\
\hline
\end{tabular}

Figure 2. Kinetics of IL-4 (A) and IL-10 (B) production in total lymphocytes from phytohemagglutinin (PHA)-, purified protein derivative (PPD)- or Mycobacterium leprae-stimulated peripheral blood mononuclear cells of tuberculosis or leprosy patients, respectively. The dashed lines and diamonds indicate non-stimulated cultures (medium), the squares indicate PPD-stimulated cultures, the triangles indicate PHA-stimulated cultures, and the asterisks indicate $M$. leprae-stimulated cultures. Data are reported as means \pm SEM (N = 3) obtained from antigens (Mycobacterium antigens, $10 \mu \mathrm{g} / \mathrm{ml}$, and $1 \%$ PHA) plus cells additionally stimulated with PMA, ionomycin and brefeldin A.

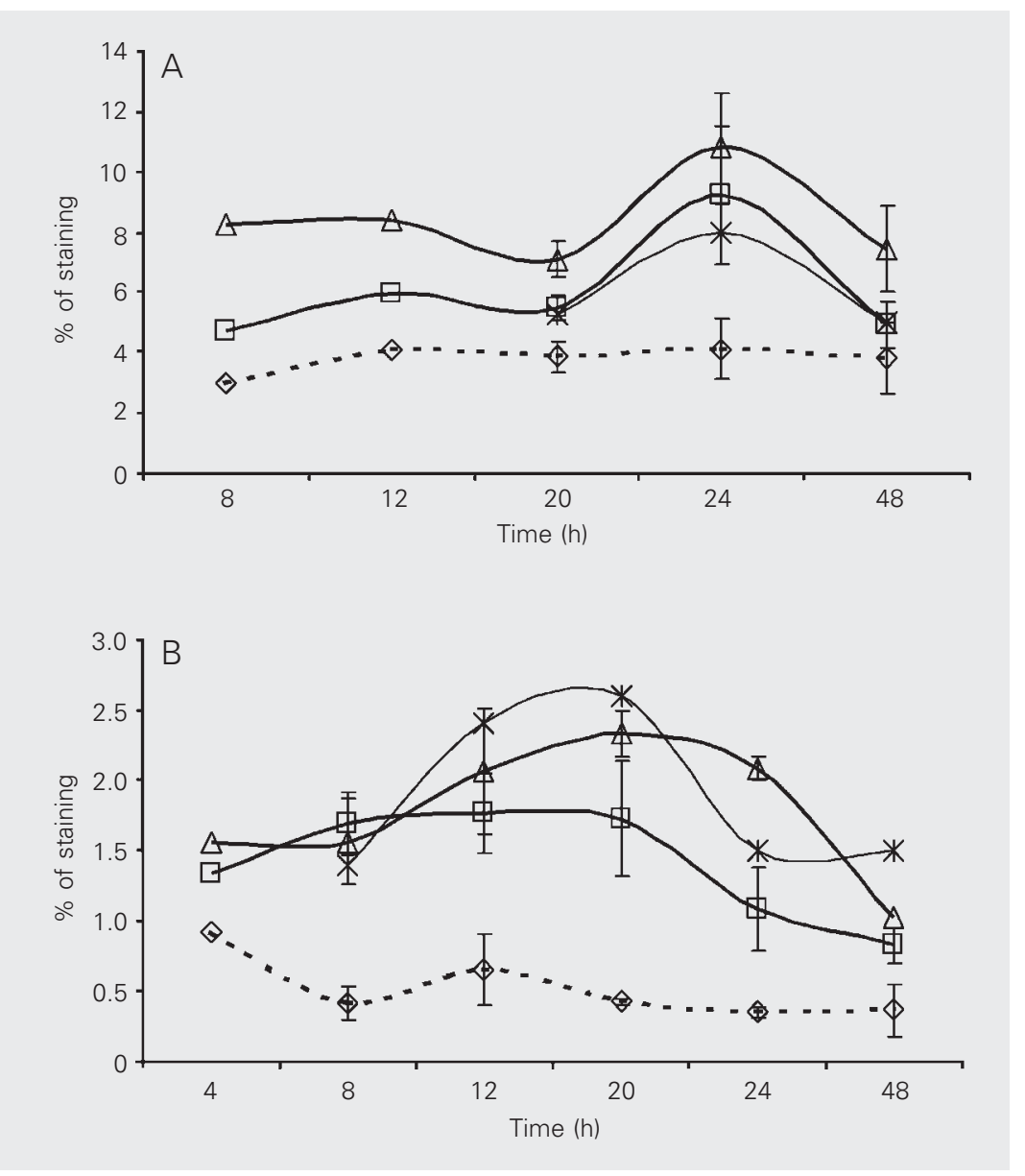


tion, followed by restimulation with a mitogen (6). The kinetics of IL-4 and IL-10 production by lymphocytes was determined in vitro as described above in 2 other tuberculosis patients and in 1 leprosy patient. Again, the immune response to PPD was positive (IFN- $\gamma$ levels $>100 \mathrm{pg} / \mathrm{ml}$ ) by ELISA in these next 3 patients (data not shown). IL-4 is also produced by mitogens-stimulated T cells (19) and, therefore we first used stimulation with PHA to induce both IL-4 and IL-10 production. With this procedure, it was possible to detect IL-4- and IL-10-producing cells following primary stimulation with PHA, $M$. leprae or PPD, and subsequent PMA + ionomycin addition, in contrast to the results obtained by others using an experimental model (20). As shown in Figure 2A, the peak of IL-4 synthesis in response to these 3 stimuli occurred after one day. At that time, the cells showed a high percentage of cytokine levels, except for the cells of one patient stimulated with PHA (12 h). Therefore, the highest IL4 production occurred at $24 \mathrm{~h}$.

Early IL-10 production was also detected, since kinetic studies conducted between 4 and $48 \mathrm{~h}$ showed the peak of synthesis of this cytokine at about $20 \mathrm{~h}$, with a rapid reduction thereafter (Figure 2B). Here, as also observed for TNF- $\alpha$, a high background level was detected earlier at $4 \mathrm{~h}$ of culture. IL-4 and IL-10 production was markedly reduced after $48 \mathrm{~h}$, while IL-10 remained relatively stable for the same period of time in only one leprosy patient. Positive responses to PHA were detected in all patients tested (data not shown).

\section{Immunophenotyping profile for intracellular IFN- $\boldsymbol{\gamma}$ and TNF- $\alpha$ in T cell subsets among tuberculosis and leprosy patients}

To validate our previous kinetic study, we performed a single study in another tuberculosis and leprosy patient panel from the same endemic region. Each protocol can be combined with surface labeling in order to determine the phenotype of cytokine-secreting cells. Thus, we carried out doublefluorescence staining experiments to detect which $\mathrm{T}$ cell subsets might produce the large amounts of IFN- $\gamma$ and TNF- $\alpha$ observed previously but using different groups of patients.

A decrease of $>95 \%$ of human CD4 and CD8 T cells following incubation with PMA + ionomycin has been reported (21-23). Therefore, to circumvent this problem, we slightly modified our protocol by replacing these reagents with a more physiological second signal triggering molecule, the purified anti-human CD28 antibody, after stimulation with specific antigen for the next step. The use of anti-CD28 antibody as a costimulatory signal for rapid cytokine production by $\mathrm{T}$ cells has been described recently, giving satisfactory results with our system and others $(15,24,25)$. Accordingly, we also assayed, in parallel, some stimulated PBMC cultures in the absence of anti-CD28 antibody. There was an average $10 \%$ decrease in specific staining for IFN- $\gamma$ (data not shown).

Therefore, further in vitro priming of $\mathrm{T}$ cells with purified anti-CD28 for $5 \mathrm{~h}$ followed by incubation of brefeldin $\mathrm{A} 1 \mathrm{~h}$ after was required to stimulate cells to produce the cytokines. Figure 3 shows representative experiments of the double-staining pattern using the same antibodies to IFN- $\gamma$ and TNF- $\alpha$ as above, in PPD- or M. leprae-stimulated CD4+ and CD8+ $\mathrm{T}$ cells from tuberculosis and leprosy patients, respectively, compared to baseline (medium) in CD4+ T cells. All of the 10 tuberculosis patients studied (100\%) showed positive $\mathrm{T}$ cell staining for IFN- $\gamma$, and 5 of 5 (100\%) showed CD4+-positive staining for TNF- $\alpha$ production. Four of $5(80 \%)$ showed positive staining for TNF- $\alpha$ production by CD8 $+\mathrm{T}$ cells in response to PPD $(\mathrm{P}=0.09$, when compared to medium in small lymphocytes). For comparison purposes, Table 1 lists the percentages of cytokine production by these $T$ cell subset populations. In the present cohort of tuberculosis patients, the in vitro 

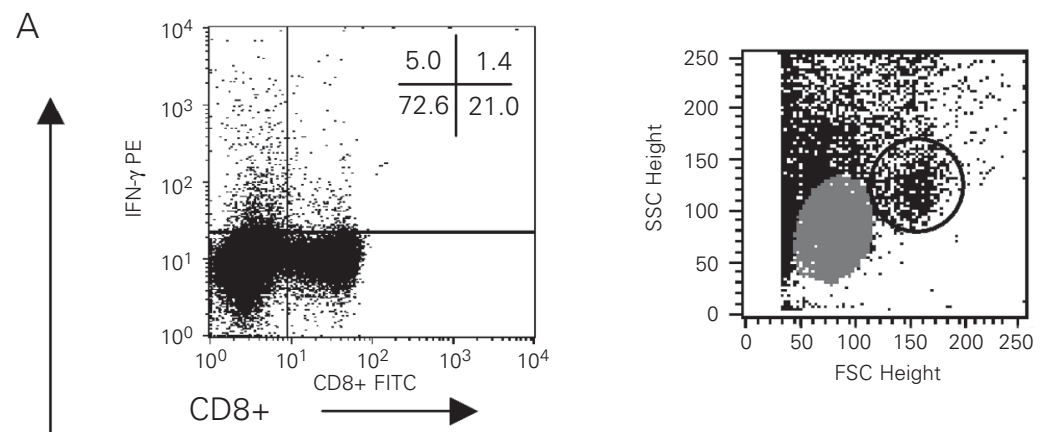

$$
\mid
$$

IFN- $\gamma$
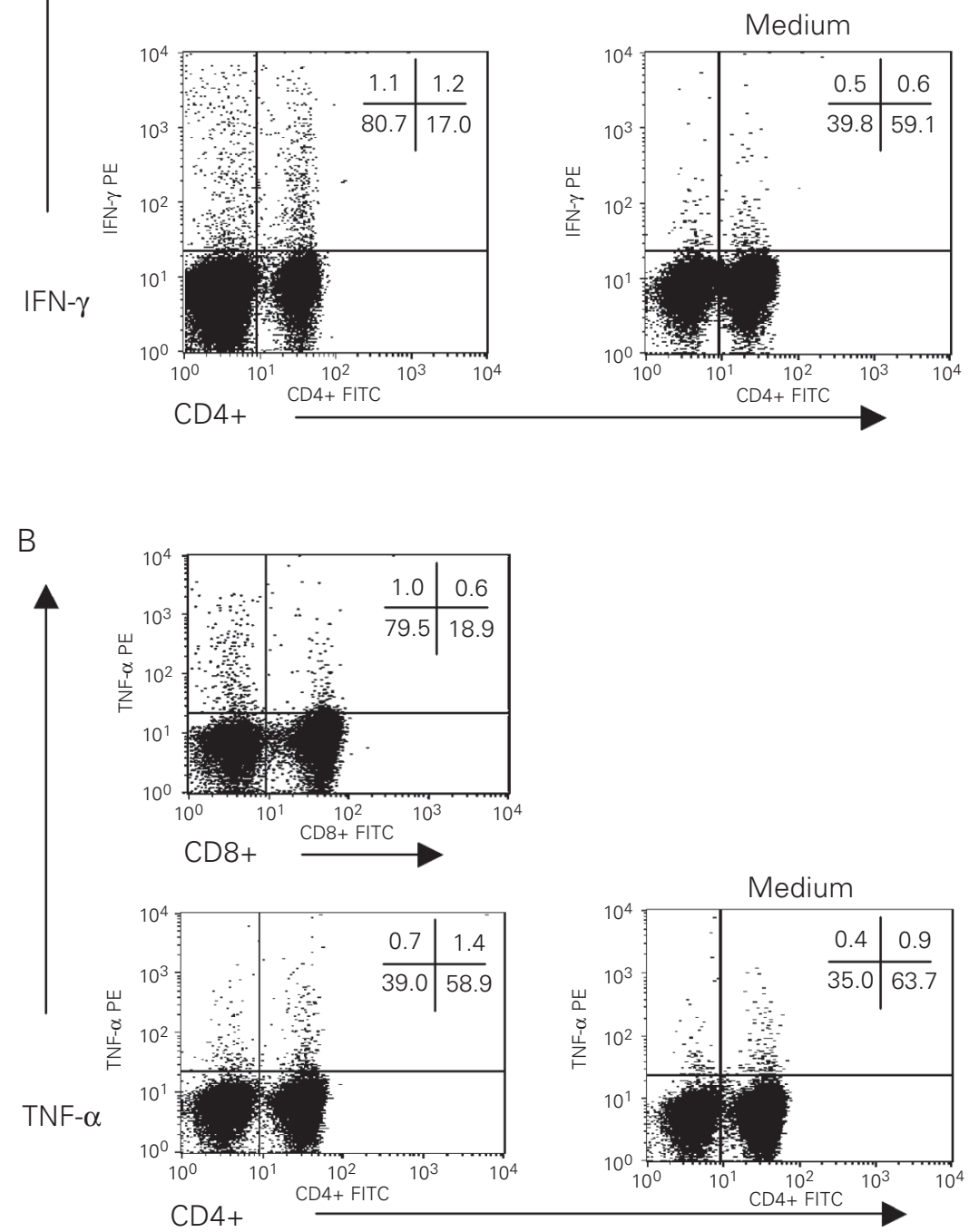

Figure 3. Typical profiles of IFN- $\gamma(\mathrm{A})$ and TNF- $\alpha$ (B) intracellular expression in CD4+ and CD8+ T cells from purified protein derivative- or Mycobacterium leprae-stimulated peripheral blood mononuclear cells, respectively. Cytokine production after specific antigenic stimuli $(10 \mu \mathrm{g} / \mathrm{ml})$ was enhanced by the addition of purified anti-human CD28 antibody (at 3 $\mu \mathrm{g} / \mathrm{ml}$ ) and brefeldin A in representative tuberculosis and leprosy patients. The inset in A shows the light scattering of the two distinct populations (gray and circle regions indicating small and blast cells, respectively) gated on the basis of their properties. Percentages of cells for the respective quadrants are indicated in each plot.
IFN- $\gamma$ and TNF- $\alpha$ response to PPD was enhanced among treated patients compared to untreated ones (Antas P, Cardoso F, Pereira K, Oliveira E, Sarno E, Franken K, Milagres A, Klatser P, Ottenhoff T and Sampaio E, unpublished data). More importantly, however, the difference between these $\mathrm{T}$ cell subsets in terms of IFN- $\gamma$ production by PPD has not been consistent, in contrast to TNF- $\alpha$ which showed a 2.4-fold increase of CD4+ compared to CD8+ $\mathrm{T}$ cells $(\mathrm{P}<0.05)$. Eleven of 13 leprosy patients $(85 \%)$ showed mainly TNF- $\alpha$ production by $\mathrm{CD} 4+\mathrm{T}$ cells, while all $(100 \%)$ showed that $\mathrm{CD} 8+\mathrm{T}$ cells primarily yielded TNF- $\alpha$ in response to $M$. leprae. Likewise, the data for the percentages of TNF- $\alpha$ production by these $\mathrm{T}$ cell subsets for leprosy patients are presented in Table 1. Like tuberculosis patients, leprosy patients also showed an increase in $\mathrm{CD} 4+$ cells ranging from 2.3- $(M$. leprae, $\mathrm{P}<0.05)$ and 2.5- ( $\mathrm{PPD}, \mathrm{P}<0.05)$ to 3.1-fold ( $\mathrm{PHA}, \mathrm{P}=0.07$ ) compared to $\mathrm{CD} 8+\mathrm{T}$ cells.

For comparative analysis, we also attempted to detect the potential presence of IFN- $\gamma$ and TNF- $\alpha$ in some blast populations from both $T$ cell subsets, since there was not enough time for our short-term bulk cultures to yield a large amount of blast cells for FACS counting (inset in Figure 3A). We observed an increase of background staining in this case, and all comparative results are summarized in Table 1. Finally, the results regarding the immunological differences inherent to leprosy and tuberculosis patients can be explored in terms of TNF- $\alpha$ staining (Table 1).

\section{Discussion}

The detection of intracellular cytokines by flow cytometry has been used in several studies (3-5). However, to our knowledge, no report concerning the optimization of this technique to measure the frequency of human Mycobacterium-specific IFN- $\gamma$-, TNF$\alpha$-, IL-4- and IL-10-producing $\mathrm{T}$ cells by 
short-term bulk culture has been reported thus far.

In the first step of the present study, antigenic in vitro stimulation for IFN- $\gamma$, TNF$\alpha$, IL-4 and IL-10 production required incubation of PBMC with PMA + ionomycin for $5 \mathrm{~h}$ in the presence of brefeldin A. The highest frequency of cells producing IL-4, IL-10 and TNF- $\alpha$ was observed at 24, 20 and $8 \mathrm{~h}$, respectively, in agreement with an earlier report (26). The highest frequencies of IFN- $\gamma$ cells were seen at about $16 \mathrm{~h}$, as also reported by others $(26,27)$. It is noteworthy that high background levels of TNF- $\alpha$ and IL-10 were detected in PBMC cultures at 4 $\mathrm{h}$, even without the addition of Mycobacterium antigens. This may probably reflect an initial, nonspecific adhesion process of mononuclear cells to the bottom of plastic culture dishes, since both endotoxic assay and later time points ruled out any contamination (16, and DeLuca P, personal communication).

We describe here the detection of intracytoplasmic cytokines by flow cytometry in order to circumvent some technical limitations imposed by ELISA. The advantage of flow cytometry using two different fluorescent dyes is the identification of single-cells and the cytokines they produce, as well as the ability to measure the kinetics of cytokine production (28). However, detection of cytokine production by FACS intracellular staining is probably less sensitive than ELISA, as indicated by the fact that the frequencies of IL-10-producing cells after PHA and PMA plus ionomycin stimulation are usually close to the FACS detection limit ( 0.1 to $2.0 \%$ ), whereas, with these stimuli, the quantities of secreted protein measured by ELISA are far above the detection limit of the method (data not shown). Additional experiments are required to improve the parameters for determining the amounts of IL4 and IL-10 produced. Thus, the use of intracellular cytokine staining, expressed as percentage of positive cells, may be a more suitable, reliable and reproducible method than ELISA.

It should be emphasized that these two methods give different types of results (amount of protein $v$ f frequency of cytokineproducing cells), and thus may lead to different interpretations of the data. Differences in the percentage of stained cells may reflect the net amount of secreted protein (3). Indeed, cytokine levels accumulated in culture supernatants represent the net balance between autocrine or paracrine consumption and the amount of secreted cytokine, which is itself influenced by several parameters including the rate of cytokine synthesis, intracellular transport, accumulation in granules, and secretion. A clear example is shown here by the peak in kinetics of IFN- $\gamma$, mainly between 20 and $24 \mathrm{~h}$, when comparing FACS and ELISA data. By contrast, intracellular cytokines may be solely dependent upon the level of cytokine synthesis, and not secretion, since most cell cultures were performed in the presence of an inhibitor of trans-Golgi protein transport that blocks cytokine secretion and leads to intracellular cytokine accumulation.

Several groups have also reported the use of multi-parameter flow cytometry for assessment of single-cell intracellular cytokine production in human $\operatorname{PBMC}(3,28,29)$. The main strengths of the method are the ability to distinguish between Th1 and Th2 cells, to examine cytokine production in rare cell populations and also to analyze cytokine production at the level of individual cells (17).

We also evaluated the stimulation protocols for IFN- $\gamma$ and TNF- $\alpha$ production by human PBMC. We used double-color flow cytometry analysis for the detection of intracellular cytokines both in PPD- and M. lepraestimulated CD4+ and CD8+ T cells, for the same period of $5 \mathrm{~h}$ with anti-CD28 in the presence of brefeldin A. Importantly, the addition of anti-CD28 antibody increased the specific staining for IFN- $\gamma$ by about $10 \%$. As expected, lower frequencies of double- 
positive cells were achieved in peripheral blood, although we confirm here that helper lymphocytes are a larger source of TNF- $\alpha$ than $\mathrm{CD} 8+\mathrm{T}$ cells. We are now performing additional experiments using enriched $\mathrm{T}$ cell populations that could circumvent this problem (30). The difference between $T$ cell subsets in terms of IFN- $\gamma$ production by PPD is not consistent and fits the initial proposal of our group and others: CD8+ T cells play an important role as a source of in vitro IFN$\gamma$ secretion $(15,30)$. More recently, memory $\mathrm{CD} 8+\mathrm{T}$ cells have been reported to be a possible early in vivo source of IFN- $\gamma$ in response to bacterial products (31). In addition, a study is currently in progress in our laboratory to improve the phenotyping analysis associated with intracellular IL-4 and IL-10 staining, with the initial results obtained being too preliminary to be presented here.

Overall, our data suggest that, in addition to permitting the identification of the cytokine-producing cell phenotype, intracellular cytokine staining by flow cytometry might be more reliable than ELISA for the biologi- cal follow-up of clinical samples. This method will be useful for analyzing the nature of immunity after a variety of antigenic stimuli, and allow us to improve understandings of the complex relationship between mycobacteria and immune system, which is fundamental in order to develop new prophylactic and diagnostic tools for control strategies. Further studies to determine the use of this protocol for the study of in vitro Mycobacterium-immune responses would be helpful also to clarify the pathogenesis of both tuberculosis and leprosy.

\section{Acknowledgments}

The authors are grateful to Drs. Paula M. DeLuca and Léa C. Filkenstein (IOC/ FIOCRUZ) for support with some technical procedures, to Dr. José A. Neri and the nursing staff of the Ambulatório Souza Araújo (FIOCRUZ) and tuberculosis wards for help with patients recruitment, and to Ms. Judy Grevan and Dr. Smita Y. Patel (NIAID/NIH) for editing the text for publication.

\section{References}

1. Kroemer G, Moreno de Alboran I, Gonzalo JÁ \& Martinez C (1993). Immunoregulation by cytokines. Critical Reviews in Immunology, 13: 163-191

2. Carter LL \& Swain SL (1997). Single cell analyses of cytokine production. Current Opinion in Immunology, 9: 177-182.

3. Jung T, Schauer U, Heusser C, Neumann C \& Rieger C (1993). Detection of intracellular cytokines by flow cytometry. Journal of Immunological Methods, 159: 197-207.

4. Vikingsson A, Pederson K \& Muller D (1994). Enumeration of IFNgamma producing lymphocytes by flow cytometry and correlation with quantitative measurement of IFN-gamma. Journal of Immunological Methods, 173: 219-228.

5. Prussin C \& Metcalfe DD (1995). Detection of intracytoplasmic cytokine using flow cytometry and directly conjugated anti-cytokine antibodies. Journal of Immunological Methods, 188: 117-128.

6. Sander B, Andersson J \& Andersson U (1991). Assessment of cytokines by immunofluorescence and the paraformaldehyde-saponin procedure. Immunological Reviews, 119: 65-93.

7. Tanaka M, Hirabayashi Y, Gatanaga $\mathrm{H}$ et al. (1999). Reduction in interleukin-2-producing cells but not Th1 to Th2 shift in moderate and advanced stages of human immunodeficiency virus type-1- infection: direct analysis of intracellular cytokine concentrations in CD4+ CD8- T cells. Scandinavian Journal of Immunology, 50: 550554.

8. Kerttula TO, Collin P, Maki M \& Hurme M (1999). Normal T-helper 1/ T-helper 2 balance in peripheral blood of coeliac disease patients. Scandinavian Journal of Immunology, 49: 197-202.

9. O'Mahony L, Holland J, Jackson J, Feighery C, Hennessy TP \& Mealy K (1998). Quantitative intracellular cytokine measurement: age-related changes in proinflammatory cytokine production. Clinical and Experimental Immunology, 113: 213-219.

10. Kemp K, Hviid L, Kharazmi A \& Kemp M (1997). Interferon-gamma production by human $T$ cells and natural killer cells in vitro in response to antigens from the two intracellular pathogens $\mathrm{Myco-}$ bacterium tuberculosis and Leishmania major. Scandinavian Journal of Immunology, 46: 495-499.

11. Dastur DK, Lalitha VS, Udani PM \& Parekh U (1970). The brain and meninges in tuberculous meningitis - gross pathology in 100 cases and pathogenesis. Neurology India, 18: 86-100.

12. Sieling PA \& Modlin RL (1994). Cytokine patterns at the site of mycobacterial infection. Immunobiology, 191: 378-387.

13. Stenger S \& Modlin RL (1999). T cell mediated immunity to Myco- 
bacterium tuberculosis. Current Opinion in Microbiology, 2: 89-93.

14. Lewis CE (1991). Detecting cytokine production at the single-cell level. Cytokine, 3: 184-188.

15. Cardoso FLL, Antas PRZ, Milagres AS et al. (2002). T cell responses to the Mycobacterium tuberculosis specific antigen ESAT-6 in Brazilian tuberculosis patients. Infection and Immunity, 70: 6707-6714.

16. Sampaio EP, Kaplan G, Miranda A, Nery JA, Miguel CP, Viana SM \& Sarno EN (1993). The influence of thalidomide on the clinical and immunologic manifestation of erythema nodosum leprosum. Journal of Infectious Diseases, 168: 408-414.

17. Prussin C (1997). Cytokine flow cytometry: understanding cytokine biology at the single-cell level. Journal of Clinical Immunology, 17: 195-204.

18. de Caestecker MP, Telfer BA, Hutchinson IV \& Ballardie FW (1992). The detection of intracytoplasmic interleukin-1 alpha, interleukin-1 beta and tumour necrosis factor alpha expression in human monocytes using two colour immunofluorescence flow cytometry. Journal of Immunological Methods, 154: 11-20.

19. Kubota E, McKenzie DT, Dutton RW \& Swain SL (1991). Role of T cells in the B-cell response: glutaraldehyde-fixed T-helper hybridoma cells synergize with the lymphokine IL-4 to induce B-cell activation and proliferation. Immunology, 72: 40-47.

20. Caraher EM, Parenteau M, Gruber H \& Scott FW (2000). Flow cytometric analysis of intracellular IFN-gamma, IL-4 and IL-10 in CD3(+)4(+) T-cells from rat spleen. Journal of Immunological Methods, 244: 29-40.

21. Ruegg CL, Rajasekar S, Stein BS \& Engleman EG (1992). Degradation of CD4 following phorbol-induced internalization in human $T$ lymphocytes. Evidence for distinct endocytic routing of CD4 and CD3. Journal of Biological Chemistry, 267: 18837-18843.

22. Anderson SJ \& Coleclough C (1993). Regulation of CD4 and CD8 expression on mouse T cells. Active removal from the cell surface by two mechanisms. Journal of Immunology, 151: 5123-5134.
23. Nakayama K \& Nakauchi H (1993). Cyclosporin A inhibits the decrease of CD4/CD8 expression induced by protein kinase $\mathrm{C}$ activation. International Immunology, 5: 419-426.

24. Waldrop SL, Pitcher CJ, Peterson DM, Maino VC \& Picker LJ (1997). Determination of antigen-specific memory/effector CD4+ T cell frequencies by flow cytometry: evidence for a novel, antigen-specific homeostatic mechanism in HIV-associated immunodeficiency. Journal of Clinical Investigation, 99: 1739-1750.

25. Suni MA, Picker LJ \& Maino VC (1998). Detection of antigen-specific $T$ cell cytokine expression in whole blood by flow cytometry. Journal of Immunological Methods, 212: 89-98.

26. Nomura LE, Walker JM \& Maecker HT (2000). Optimization of whole blood antigen-specific cytokine assays for CD4(+) T cells. Cytometry, 40: 60-68.

27. Santiago MA, Luca PM, Bertho AL, Azeredo-Coutinho RB \& Coutinho SG (2000). Detection of intracytoplasmic cytokines by flow cytometry. Memórias do Instituto Oswaldo Cruz, 95: 401-402.

28. Elson LH, Nutman TB, Metcalfe DD \& Prussin C (1995). Flow cytometric analysis for cytokine production identifies $\mathrm{T}$ helper 1, T helper 2, and T helper 0 cells within the human CD4+CD27- lymphocyte subpopulation. Journal of Immunology, 154: 4294-4301.

29. Mascher B, Schlenke P \& Seyfarth M (1999). Expression and kinetics of cytokines determined by intracellular staining using flow cytometry. Journal of Immunological Methods, 223: 115-121.

30. Smith SM, Klein MR, Malin AS, Sillah J, Huygen K, Andersen P, McAdam KP \& Dockrell HM (2000). Human CD8(+) T cells specific for Mycobacterium tuberculosis secreted antigens in tuberculosis patients and healthy BCG-vaccinated controls in the Gambia. Infection and Immunity, 68: 7144-7148.

31. Kambayashi $T$, Assarsson $E$, Lukacher AE, Ljunggren HG \& Jensen PE (2003). Memory CD8+ T cells provide an early source of IFNgamma. Journal of Immunology, 170: 2399-2408. 